\title{
Osteopontin promotes fibrosis in dystrophic mouse muscle by modulating immune cell subsets and intramuscular TGF- $\beta$
}

\author{
Sylvia A. Vetrone, ${ }^{1,2}$ Encarnacion Montecino-Rodriguez, ${ }^{3}$ Elena Kudryashova, ${ }^{1}$ Irina Kramerova, \\ Eric P. Hoffman, ${ }^{4}$ Scot D. Liu, ${ }^{5}$ M. Carrie Miceli, ${ }^{5}$ and Melissa J. Spencer ${ }^{1}$

\begin{abstract}
${ }^{1}$ Department of Neurology, ${ }^{2}$ Molecular, Cellular and Integrative Physiology Program, and ${ }^{3}$ Department of Pathology and Laboratory Medicine, David Geffen School of Medicine, UCLA, Los Angeles, California, USA. ${ }^{4}$ Children's National Medical Center, Washington, DC, USA. ${ }^{5}$ Department of Microbiology and Molecular Genetics, David Geffen School of Medicine, UCLA, Los Angeles, California, USA.
\end{abstract}

\begin{abstract}
Duchenne muscular dystrophy (DMD) is an X-linked, degenerative muscle disease that is exacerbated by secondary inflammation. Here, we characterized the immunological milieu of dystrophic muscle in $m d x$ mice, a model of DMD, to identify potential therapeutic targets. We identified a specific subpopulation of cells expressing the $V \beta \beta$ 8.1/8.2 TCR that is predominant among TCR $-\beta^{+} T$ cells. These cells expressed high levels of osteopontin (OPN), a cytokine that promotes immune cell migration and survival. Elevated OPN levels correlated with the dystrophic process, since OPN was substantially elevated in the serum of $m d x$ mice and muscle biopsies after disease onset. Muscle biopsies from individuals with DMD also had elevated OPN levels. To test the role of OPN in $m d x$ muscle, mice lacking both OPN and dystrophin were generated and termed doublemutant mice (DMM mice). Reduced infiltration of NKT-like cells and neutrophils was observed in the muscle of DMM mice, supporting an immunomodulatory role for OPN in $m d x$ muscle. Concomitantly, an increase in $\mathrm{CD}^{+}$and FoxP3 ${ }^{+}$Tregs was also observed in DMM muscle, which also showed reduced levels of TGF- $\beta$, a known fibrosis mediator. These inflammatory changes correlated with increased strength and reduced diaphragm and cardiac fibrosis. These studies suggest that OPN may be a promising therapeutic target for reducing inflammation and fibrosis in individuals with DMD.
\end{abstract}

\section{Introduction}

Muscle damage due to muscular dystrophy is associated with muscle inflammation, which is a secondary feature that can exacerbate disease. In particular, muscle inflammation exacerbates pathology in the $m d x$ mouse, an animal model for the human disease Duchenne muscular dystrophy (DMD). The $m d x$ mouse has a naturally occurring mutation in the gene encoding the cytoskeletal-protein dystrophin. Muscles of the $m d x$ mouse undergo a moderate dystrophy with a predictable course, consisting of an early prenecrotic period (1-3 weeks of age), followed by a wave of necrosis at 3.5 weeks that continues until 8 weeks of age. Because of the predictable disease course and the distinct phases observed, it is informative to examine specific points in the life of the mouse to gain insight into processes of muscle degeneration, regeneration, and fibrosis. For example, at 3.5-4 weeks of age, information can be gained about necrotic and regenerative processes. By $6-12$ months of age, the diaphragms and hearts of $m d x$ mice are fibrotic, so the study of mice at this age can lend insight into fibrotic processes.

Muscle lesions of $m d x$ mice are filled with invading cells from the immune system that include T cells (1), macrophages (2), neutrophils (3), mast cells (4), and eosinophils (5, 6). Similarly, an inflammatory mRNA signature has been detected in DMD biopsies soon after birth (7). Several previous studies have demonstrated that experimental interventions that reduce subsets of immune cells

Conflict of interest: The authors have declared that no conflict of interest exists.

Nonstandard abbreviations used: DMD, Duchenne muscular dystrophy; dMHC, developmental myosin heavy chain; DMM mice, double-mutant mice; DPBS, Dulbecco's PBS; OPN, osteopontin; QPCR, quantitative real-time PCR.

Citation for this article: J. Clin. Invest. 119:1583-1594 (2009). doi:10.1172/JCI37662. in vivo can reduce muscle pathology in the $m d x$ mouse $(1,2,8,9)$. Depletion of CD8 ${ }^{+} \mathrm{T}$ cells (10), CD4 ${ }^{+} \mathrm{T}$ cells (1), macrophages (2), eosinophils (6), neutrophils (3), and TNF (11-15) or treatment with immunosuppressants $(9,14)$ have all been shown to improve pathogenic features of the disease in mouse models. These studies support a role for the immune system as an exacerbating factor that promotes muscle pathology in the muscular dystrophies and suggest that interventions that target these invading cells might provide therapeutic benefit.

Diaphragm and cardiac fibrosis are hallmark characteristics of pathology resulting from dystrophin mutations that cause marked functional impairment in boys with DMD. In the $m d x$ mouse, only the diaphragm and heart become increasingly fibrotic, while extensive connective tissue proliferation is evident in all DMD muscles from a very young age. Despite this prominent role in dystrophic muscle, the mechanism of ECM deposition is not well understood. Fibroblasts are often presumed to be the key secreting cell; however, muscle is also capable of secreting ECM proteins (16) and will need to be considered as a source of ECM secretion. Since fibrosis is only markedly increased in the 6-month-old $m d x$ diaphragm and the 1-year-old $m d x$ heart, these muscles are often the focus of investigations that are devoted to searching for mediators of fibrosis in DMD.

A link between fibrosis and inflammation has been demonstrated in many studies using the $m d x$ mouse, with TGF- $\beta$ emerging as a key regulator of the process. TGF- $\beta$ is elevated in $m d x$ (12) and DMD muscle (17), especially in the later years of the disease (7). While the specific source of TGF- $\beta$ is still not known, fibroblasts and leukocytes are likely to be important contributors. Reductions in lymphocyte populations in $m d x$, achieved by crossing the nude (18) or SCID mouse (19) with $m d x$, correlated with reductions in fibrotic tissue 

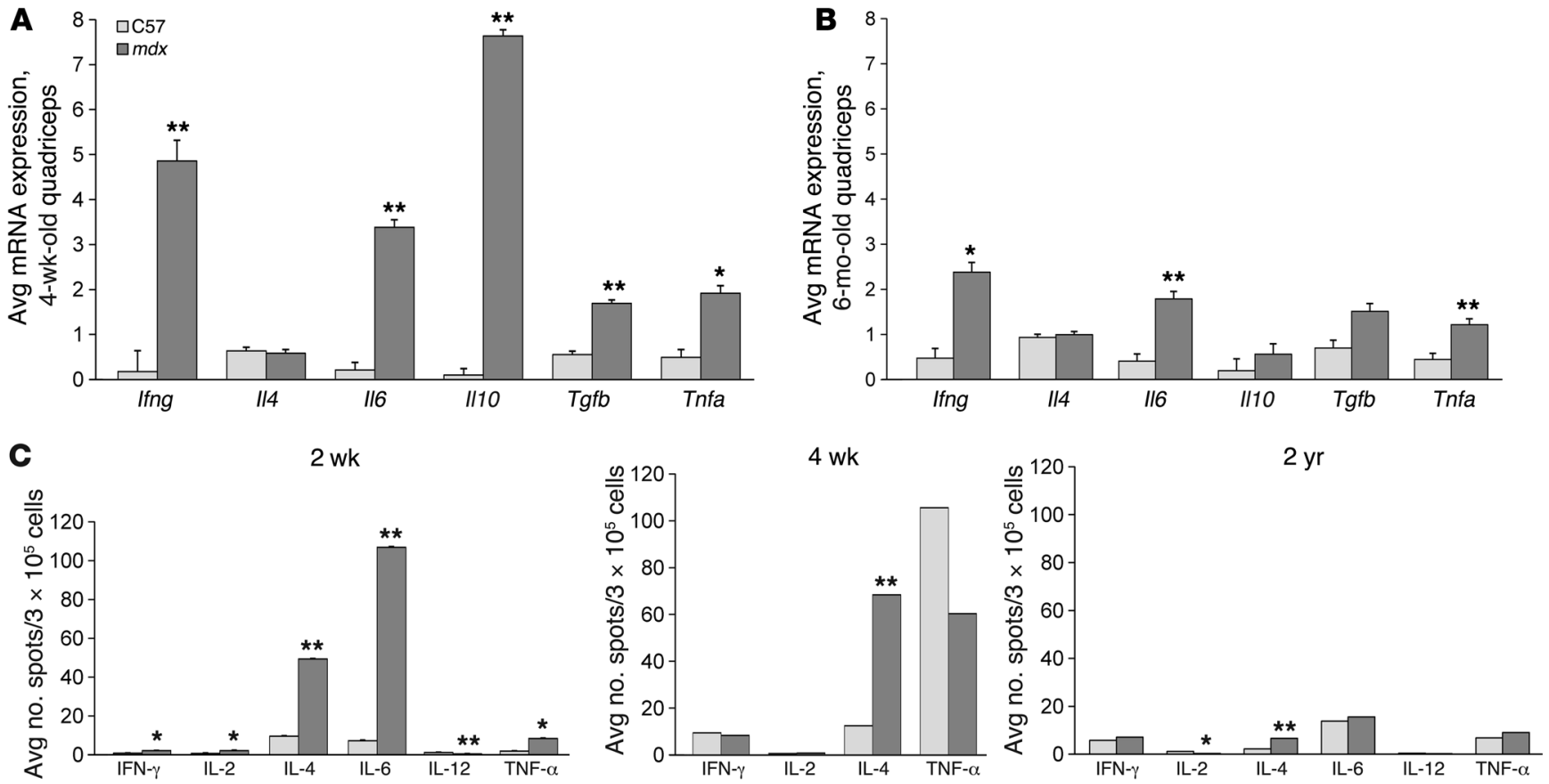

Figure 1

Characterization of inflammatory cytokines in $m d x$ muscle and spleen. Cytokine mRNA expression was assessed by QPCR in C57BL/6 (C57) and $m d x$ quadriceps muscles at $(\mathbf{A}) 4$ weeks of age $(n=4)$ and $(\mathbf{B}) 6$ months of age $(n=4)$. Expression was normalized to GAPDH mRNA. (C) Cytokine secretion was assessed in C57BL/6 and $m d x$ splenocytes by ELISPOT. Data are presented as average (avg) values. Error bars represent SEM (A and $\mathbf{B}) .{ }^{*} P \leq 0.05,{ }^{*} P \leq 0.01$.

accumulation in skeletal muscle, supporting a role for the $\mathrm{T}$ lymphocytes in promotion of fibrosis. Thus, the fibrotic process in $m d x$ muscle is complex and is expected to involve multiple cell types.

The design of effective immune-based treatments for DMD relies on the determination of the contribution of each cell type to the pathogenesis as well as an in-depth understanding of mechanisms used by these cells. Infiltrating cells can potentially play 4 different roles in the disease process, including (a) promotion of necrosis, (b) promotion of fibrosis, (c) immunomodulation, or (d) promotion of muscle repair. To suppress cells that promote necrosis or fibrosis, ideally one would specifically suppress only the cell types contributing to the pathogenesis. Conversely, immunoregulatory cells have emerged as important modulators of the immune response in several experimental systems or in promotion of muscle repair. Thus, it is feasible that treatments could be designed to attract and/or activate these specific populations in muscle to improve disease outcome. Identification of all cells infiltrating dystrophic muscle and understanding their mechanisms of action is the first step toward development of immunotherapeutics to treat DMD.

In this investigation, we identify osteopontin (OPN) as an immunomodulator in $m d x$ muscle. OPN is the primary phosphorylated glycoprotein of bone and is also expressed in a wide variety of other cells and tissues, including immune cells, skin, and blood vessels. OPN is an approximately $35-$ to $60-\mathrm{kDa}$, highly acidic, secreted and glycosylated phosphoprotein. Once secreted, OPN can be cleaved by both thrombin and MMP3 and MMP7. OPN also binds to trans-membrane proteins such as integrins (20-24) and CD44 (also known as hyaluronic acid receptor or vitronectin receptor) (25) and to the ECM molecules fibronectin and collagen
(26). Transglutamination of OPN can facilitate covalent binding to fibronectin, creating a strong adhesive link between these proteins in the ECM (26). While the earliest studies of OPN suggested that it had a central role in bone remodeling and cancer metastasis (27-30), subsequent studies demonstrated that OPN also participates in numerous other physiological processes such as formation of collagen fibrils during tissue remodeling (31), macrophage and neutrophil migration $(32,33)$, angiogenesis (28), and wound healing (31). OPN binding to integrins on the surface of immune cells is likely the mechanism by which OPN modulates chemotaxis of these cells. Thus, OPN is considered to be a matrix factor, a chemotactic factor, and a cytokine, which is expressed in numerous cell types and which possesses pleiotropic functions.

In the current investigation, we characterized the inflammatory milieu of $m d x$ muscle and, through this analysis, identified a predominant $\mathrm{T}$ cell subtype (Vß8.1/8.2+) that expresses OPN. A high concentration of OPN was observed in $m d x$ and DMD biopsies and $m d x$ serum. OPN was expressed both by muscle and immune cells. Genetic ablation of OPN from $m d x$ mice caused a considerable reduction in intramuscular neutrophils and NKT-like cells and increased Tregs. Subsequently, these inflammatory changes resulted in a net decrease in TGF- $\beta$ in later stages of the disease. Reductions in TGF- $\beta$ correlated with a marked decrease in fibrosis of both diaphragm and cardiac muscles. These studies identify OPN as an immunomodulator and profibrotic cytokine in dystrophic muscle.

\section{Results}

Characterization of the immunological milieu in $m d x$ muscle. Characterizing the immunological milieu in dystrophic muscle is the first 

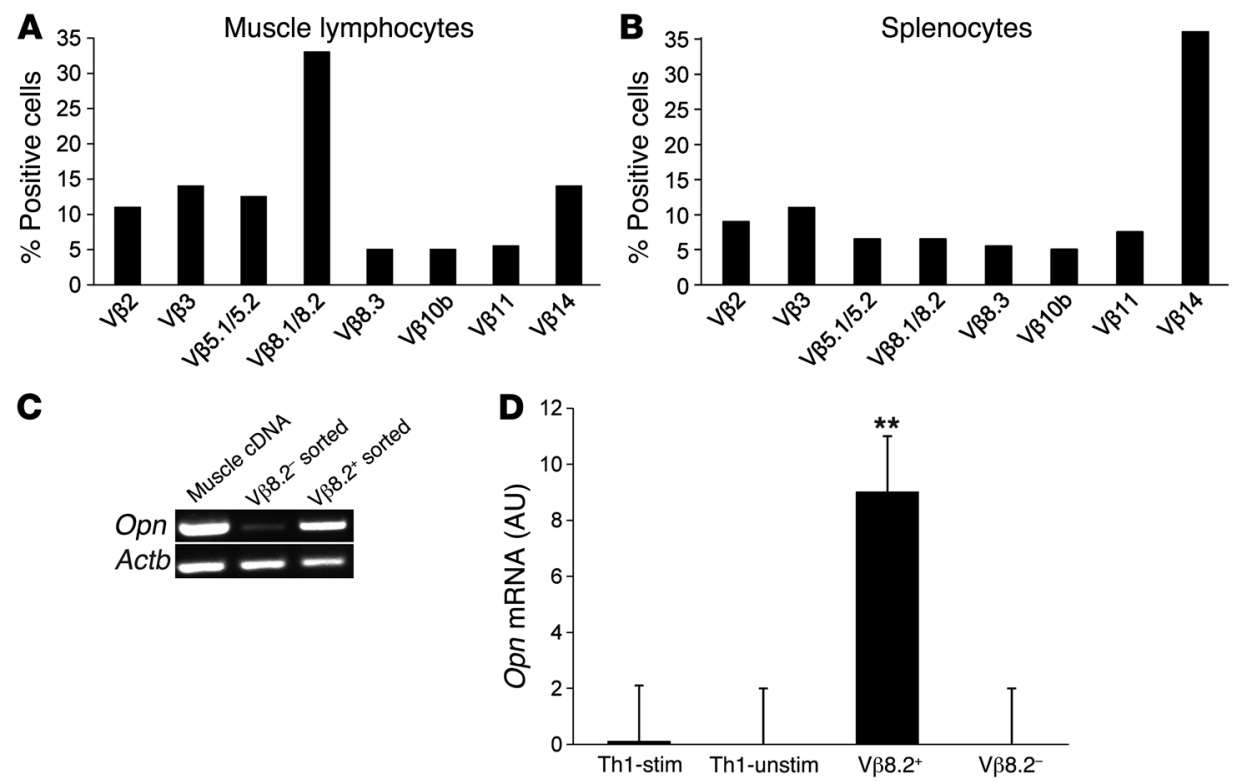

Figure 2

V $\beta 8.1 / 8.2$ is the predominant $\mathrm{V} \beta \mathrm{TCR}$ rearrangement in $m d x$ muscle. Infiltrating leukocytes were extracted, purified, and pooled from all skeletal muscles of 4-week-old $m d x$ mice, stained with various mouse $V \beta$ TCR antibodies, and analyzed by flow cytometry. A representative experiment showing the distribution of $\mathrm{V} \beta$ TCR rearrangements of leukocytes isolated from muscle $(\mathbf{A})$ and spleen $(\mathbf{B})$ is shown. A clear bias toward the $\mathrm{V} \beta$ 8.1/8.2 TCR rearrangement is observed in leukocytes isolated from muscle that is not seen in those isolated from the spleen. (C) Leukocytes, extracted, purified, and pooled from skeletal muscle of four 4-week-old $m d x$ mice, were sorted by FACS into 2 populations, V $\beta 8.1 / 8.2^{-}$and $\mathrm{V} \beta 8.1 / 8.2^{+}$, and RT-PCR for Opn mRNA expression was carried out. PCR was also carried out on RNA isolated from the quadriceps muscle. (D) Quantitative RT-PCR of OPN using the same sorted samples shown in C. Stimulated Th1 (Th1-stim) and unstimulated Th1 (Th1-unstim) cells are shown as controls. ${ }^{*} P \leq 0.01$, as assessed by 2 -tailed Student's $t$ test. Error bars represent SEM (D).

step toward identifying disease effectors, enabling development of pharmacological interventions that slow disease progression. Thus far, no parallel assessment of intramuscular cytokine profiles and cellular infiltrates has been systematically undertaken over a time course in the $m d x$ mouse. Thus, the first goal of this study was to determine whether a specific immune effector predominates in dystrophic muscle, making it an obvious candidate target for therapy. We first examined cytokine expression profiles using quantitative real-time PCR (QPCR) of $m d x$ muscles (Figure $1, \mathrm{~A}$ and $\mathrm{B}$ ) and ELISPOT of $m d x$ spleens (Figure $1 \mathrm{C}$ ) over a time course. In the quadriceps muscle, levels of many different cytokines were observed to be elevated at 4 weeks of age, including IFN- $\gamma$ and TNF- $\alpha$. While many of these levels of intramuscular cytokines remained elevated over controls at 6 months of age, their relative concentration decreased with aging (Figure 1, compare A to B). Conversely, analysis of the cytokine secretion profile of spleens using ELISPOT revealed no change in IFN- $\gamma$ and TNF- $\alpha$ levels in $m d x$ mice versus C57BL/6. Furthermore, levels of the cytokine IL-4 were elevated in $m d x$ spleens compared with C57BL/ 6 spleens but were not elevated in $m d x$ quadriceps muscle. Therefore, this analysis revealed in spleens from 4-week-old mice but not in quadriceps muscle from 4-week-old mice. Therefore, this analysis revealed an important difference between the cytokine expression pattern of spleens and muscles of $m d x$ mice and suggested that evaluation of cytokines in dystrophic mice should involve specific investigation of muscle-specific cytokine patterns and should not rely on analysis of peripheral lymphoid tissues. Cellular profiles of $m d x$ muscle infiltrates were also examined (Supplemental Figure 1; supplemental material available online with this article; doi:10.1172/JCI37662DS1). These studies showed that both myeloid and lymphoid cells infiltrate dystrophic muscles, with neutrophils being the predominant cell type (approximately 40\%). T cells represented approximately 3\% of all infiltrating cells, with over half present as double-negative T cells (lacking both CD4 and CD8 expression). NKT cells, which express both $\mathrm{T}$ and NK markers, have not been previously described in $m d x$ muscle. Cells expressing both NK and T cell markers were identified in dystrophic muscle and represented approximately $8 \%-10 \%$ of the $\mathrm{CD}^{+}$cells. These studies show that the $m d x$ milieu is diverse, involving numerous cytokines and cell types with potent immunomodulatory and immune effector activity.

$T$ lymphocytes isolated from $m d x$ muscle predominantly express the $V \beta 8.1 / 8.2$ TCR. Given that our preliminary studies did not identify a single immunomodulator as an obvious effector of intramuscular inflammation in $m d x$ mice, we chose to focus more closely on intramuscular T lymphocytes. Previous studies have shown that a specific TCR rearrangement is over represented in DMD muscles (34) and that reductions in T cells correlate with improved indicators of necrosis and fibrosis in DMD (35) and the $m d x$ mouse $(1,10,18)$. Overrepresentation of $\mathrm{T}$ cell populations expressing a restricted set of TCR variable genes could derive from clonal expansion, conserved antigen recognition, or the emergence of a regulatory population. To determine whether any TCR subtypes were overrepresented in the infiltrate, we isolated muscle-infiltrating leukocytes at the first peak of disease (4 weeks of age) and examined TCR V $\beta$ expression using flow cytometry. T cells from a diverse repertoire of $\mathrm{V} \beta$ families were represented in the infiltrate; however, in 4 out of 4 independent experiments, there was a predominance of 
Anti-goat IgG

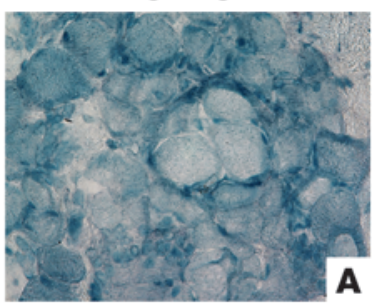

A

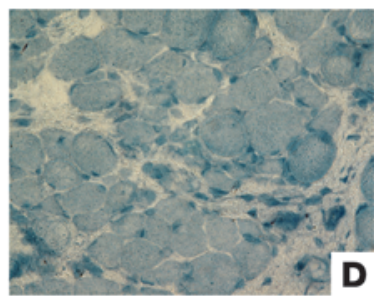

Anti-goat IgG
$1.5 \mathrm{yr}$
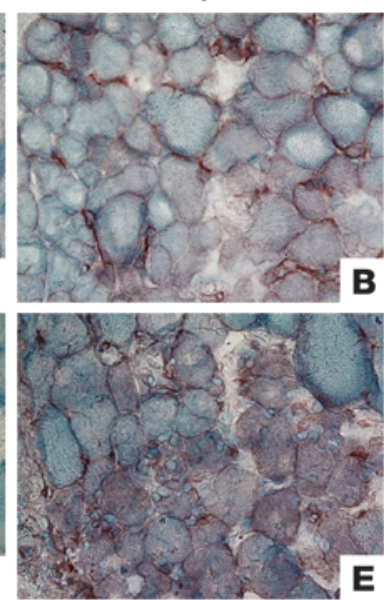

$4 \mathrm{yr}$
$3 \mathrm{yr}$
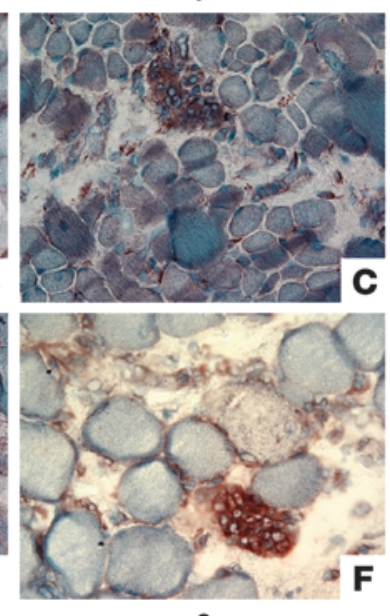

Figure 3

OPN is expressed in immune and muscle cells. Assessment of cellular distribution of OPN was performed using biopsies from patients with DMD. Cross sections were stained with goat anti-OPN (red) and counter stained with hematoxylin (blue/purple). OPN was observed in both muscle fibers that appeared to be healthy and in clusters of mononucleated cells (B, C, $\mathbf{E}$, and $\mathbf{F}$ ); thus, OPN is widely expressed in muscle and in immune cells. Negative control sections were stained with goat IgG instead of OPN antibody (A and $\mathbf{D})$. Original magnification of $\times 20$.
T cells expressing V $\beta 8.1 / 8.2$ in $m d x$ muscle (Figure $2 \mathrm{~A}$ ). On average, $\mathrm{V} \beta 8.1 / 8.2$ was expressed by approximately $30 \%$ of all $V \beta$-expressing cells (i.e., TCR- $\beta^{+}$T cells) isolated from $m d x$ muscle. In comparing the TCR V $\beta$ usage in $m d x$ muscle versus spleen, a bias toward an elevated appearance of the V $\beta 8.1 / 8.2$ TCR was observed in dystrophic muscle that was not present in the spleen (Figure 2, compare $\mathrm{A}$ and $\mathrm{B}$ ). Thus, $\mathrm{V} \beta 8.1 / 8.2^{+}$cells are not generally overrepresented in circulating cells, and, therefore, it is likely that these cells either selectively home to or expand in $m d x$ muscle.

We further examined the $V \beta 8.1 / 8.2^{+}$cells to ascertain activation in vivo. Assessment of known $\mathrm{T}$ cell activation markers revealed that the majority of cells expressing V $\beta 8.1 / 8.2$ also expressed the activation markers CD69, CD154, CD134, CD49d, and CD106 (Supplemental Table 1). Furthermore, CD69, CD106, CD134, and $\mathrm{CD} 154$ were observed at a higher frequency on $\mathrm{V} \beta 8.1 / 8.2^{+}$ cells than on all TCR- $\beta^{+}$expressing cells, suggesting that these $V \beta 8.1 / 8.2^{+}$cells might be a more active $T$ cell subtype than the general population of $\mathrm{T}$ cells.

$V \beta 8.1 / 8.2^{+}$cells secrete OPN. To gain insight into the potential role of the V $\beta 8.1 / 8.2^{+}$cells in muscular dystrophy, we examined proteins synthesized by this cell population. We analyzed $V \beta 8.1 / 8.2^{+}$ and $V \beta 8.1 / 8.2^{-}$sorted populations and found that the cytokine
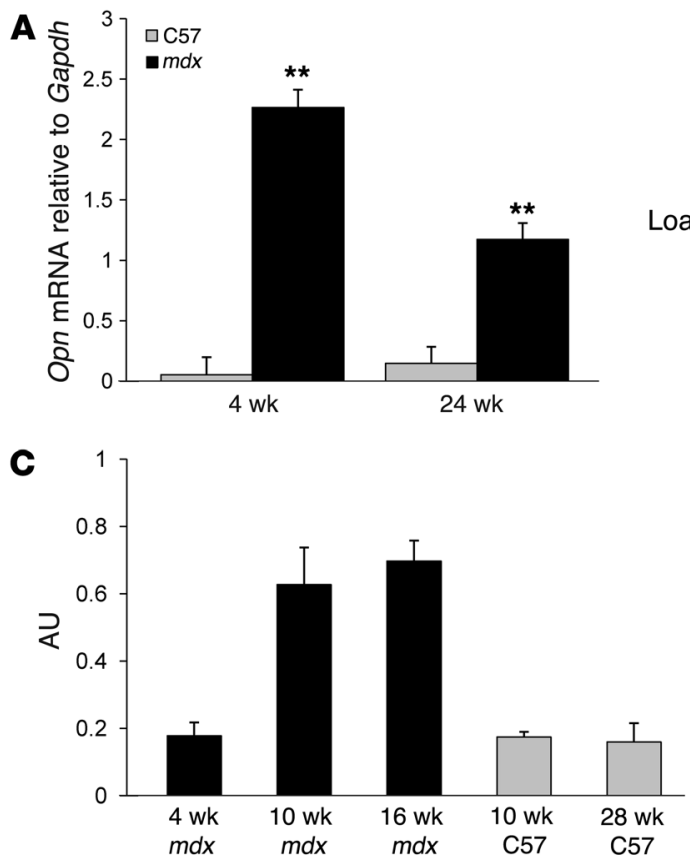

B
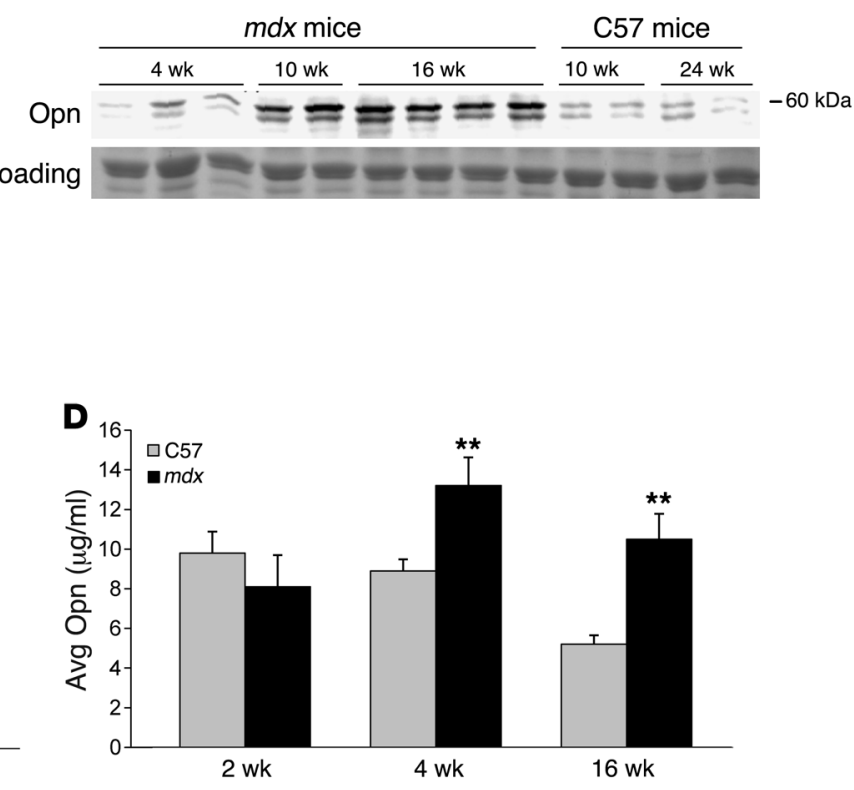

Figure 4

OPN levels are elevated in dystrophic muscle and blood. OPN levels are elevated in $m d x$ mice compared with C57BL/6 controls after disease onset. OPN was assessed by (A) QPCR of quadriceps muscles and (B) Western blot of diaphragm muscles. (C) Densitometry of the Western blot is shown in C. (D) OPN levels are also elevated in $m d x$ blood coincident with the onset of disease, as assessed by ELISA. Data are presented as average values. Error bars represent SEM (A, C, and D). ${ }^{* *} P \leq 0.01$, as assessed by a 2-tailed Student's $t$ test. 


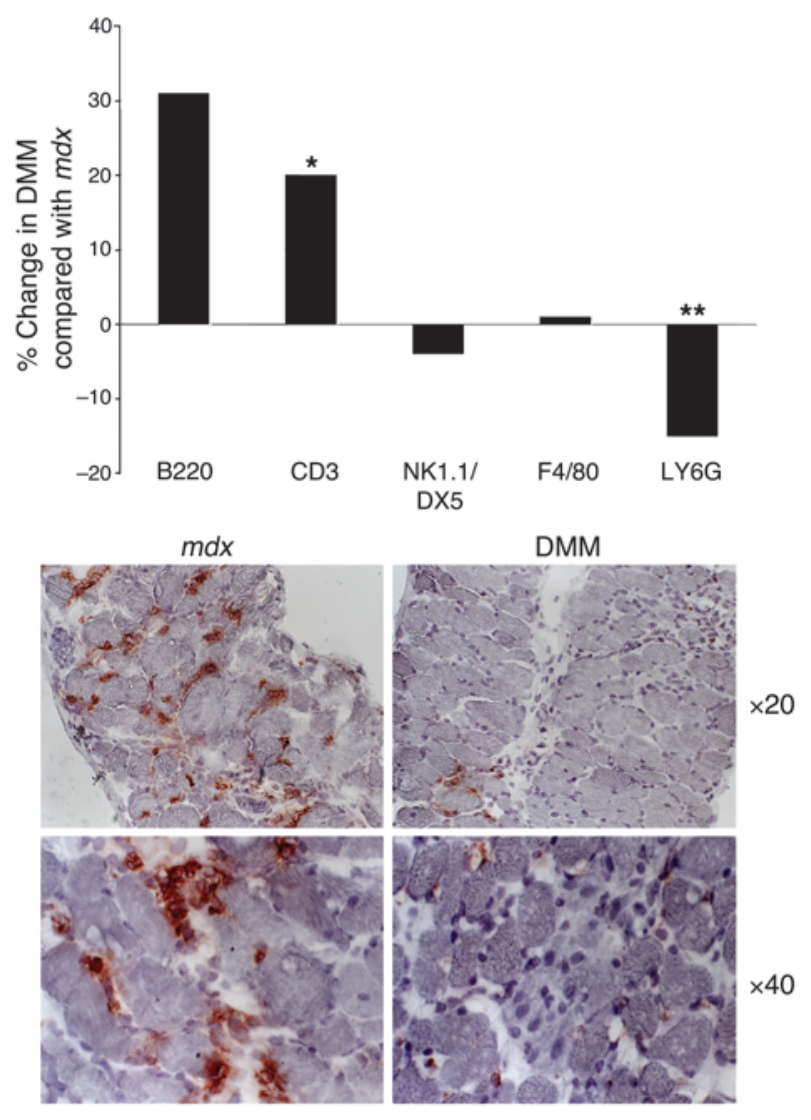

OPN was expressed at high levels in the V $\beta 8.1 / 8.2^{+}$cells. Both RT-PCR (Figure 2C) and QPCR (Figure 2D) revealed high expression of OPN in the sorted V $\beta 8.1 / 8.2^{+}$cells compared with the $\mathrm{V} \beta 8.1 / 8.2^{-}$cells. Thus through these studies, OPN emerged as a candidate modulator of inflammation, because it is secreted by a subpopulation of activated $\mathrm{T}$ cells that appear to be overrepresented in dystrophic muscle.

OPN is highly expressed in dystrophic muscle. Even though we initially identified OPN as a protein expressed by $\mathrm{T}$ lymphocytes infiltrating $m d x$ muscle, it is known that OPN is a widely expressed protein found in numerous cells types. Because dystrophic muscle contains a mixture of cell types, including muscle cells, immune cells, and fibroblasts, we sought to determine whether other cells in $m d x$ muscle besides lymphocytes might express OPN. To determine the localization of OPN in dystrophic muscle, we examined frozen sections of DMD biopsies by immunohistochemistry with OPN-specific antibodies. This analysis showed that OPN is primarily expressed by infiltrating immune cells as well as in some muscle fibers that showed light, cytoplasmic staining (Figure 3). These observations suggest that in addition to immune cells, muscle fibers could be an additional source of OPN.

The induction of OPN in both muscle and immune cells from dystrophin-deficient tissue suggests that OPN expression might also be a marker for disease activity in human muscular dystrophies. To test this, we queried the expression of OPN mRNA in a 125 muscle biopsy human data set $(36,37)$. Of DMD $(P=0.0001)$, dysferlin $(P=0.0190)$, and calpain $(P=0.0086)$ deficiencies, each showed very high and statistically significant expression of $O P N$ mRNA relative to both normal muscle, and other muscle disorders

\section{Figure 5}

Ablation of OPN leads to changes in intramuscular inflammatory cells. Infiltrating leukocytes were isolated from $m d x$ and DMM mice and characterized by flow cytometry as described in Methods. Each experiment was performed on leukocytes isolated from muscles of 4 grouped 4-week-old $m d x$ or DMM mice, which were stained for cell surface markers and analyzed by flow cytometry. Data represent the percentage difference in DMM muscles of intramuscular inflammatory cells bearing the indicated cell surface markers compared with $m d x$ muscles. Data were assessed from 6-8 experiments per stain. ${ }^{\star} P \leq 0.05,{ }^{* \star} P \leq 0.01$, as assessed by Mann-Whitney $U$ test (top panel). Cross sections of 6-month-old $m d x$ and DMM diaphragm muscles immunostained for Ly6G, a neutrophil marker (red) and counterstained for hematoxylin (blue). Original magnification of $\times 20$ (bottom panel).

(Supplemental Figure 2). Furthermore, after surveying the literature, we discovered that the mRNA for OPN was highly elevated in numerous microarray studies of $m d x$ and DMD muscle (compared with controls) (38-42). QPCR of $m d x$ muscle confirmed the high OPN expression in $m d x$ muscles at both 4 weeks and 24 weeks of age (Figure 4A). Protein studies also revealed a large increase in OPN levels in $m d x$ diaphragm muscles, which appeared highly elevated at 10 weeks of age and remained elevated at 16 weeks of age (Figure 4, B and C). Because it is a secreted protein, we assayed $m d x$ and $\mathrm{C} 57 \mathrm{BL} / 6$ serum for OPN. Serum OPN concentration was significantly elevated above that found in control mice at both 4 weeks and 24 weeks of age (Figure 4D). Thus, OPN is highly upregulated in dystrophic muscle and serum.

OPN modulates cellular immune profiles in mdx muscles. Previous studies have shown the OPN can modulate immune cell chemotaxis to tissues through its binding to CD $44, \alpha v \beta 3$, and $\alpha v \beta 5$ integrins $(20,43)$. To determine the impact of OPN on immune cell profiles in dystrophic muscle, we crossed OPN-knockout mice (on the C57BL/ 6 background) to $m d x$ mice (on the C57BL/10 background) to generate OPN-null, dystrophin-deficient, double-mutant mice (referred to as DMM mice). DMM were compared with $m d x$ littermates expressing normal levels of OPN (referred to as $m d x$ mice).

To examine the role of OPN in regulation of muscle inflammation, muscle-infiltrating leukocytes were quantitatively assessed in DMM and $m d x$ muscles. In each of 8 independent experiments, muscle leukocytes were extracted and pooled from all the muscles of 4 mice of each genotype, stained, and subjected to flow cytometry to quantitate immune cell subsets. Our analysis demonstrated a specific reduction in neutrophils but not macrophages in DMM muscles (Figure 5, Supplemental Figure 3, and Supplemental Tables 2 and 3). These studies suggest that the upregulation in OPN observed after disease onset plays a role in attracting neutrophils to dystrophic muscle.

In addition to reductions in neutrophils, we also quantitated a significant increase in $\mathrm{CD}^{+}$cells (Figure 5). To further identify these $\mathrm{CD}^{+}$-bearing cells, we gated on CD3 and examined additional cell surface markers (Figure 6A and Supplemental Table 3). This analysis revealed significant reductions in $\mathrm{CD}^{+} / \mathrm{V} \beta 8.1 / 8.2^{+}$ cells and NKT-like cells (both $\mathrm{CD}^{+} / \mathrm{DX}^{+}$and $\mathrm{CD}^{+} \mathrm{NK} 1.1^{+}$cells) in DMM muscle (Supplemental Table 3). Thus, OPN appeared to also play a role in attracting NKT-like cells to dystrophic muscle; however, these data do not explain the source of the increase in $\mathrm{CD}^{+}$cells in DMM muscles. Interestingly, a marked increase in $\mathrm{CD}^{+} / \mathrm{CD}^{+}$cells was observed. To investigate whether these cells might be Tregs, known to promote tolerance and limit activation 

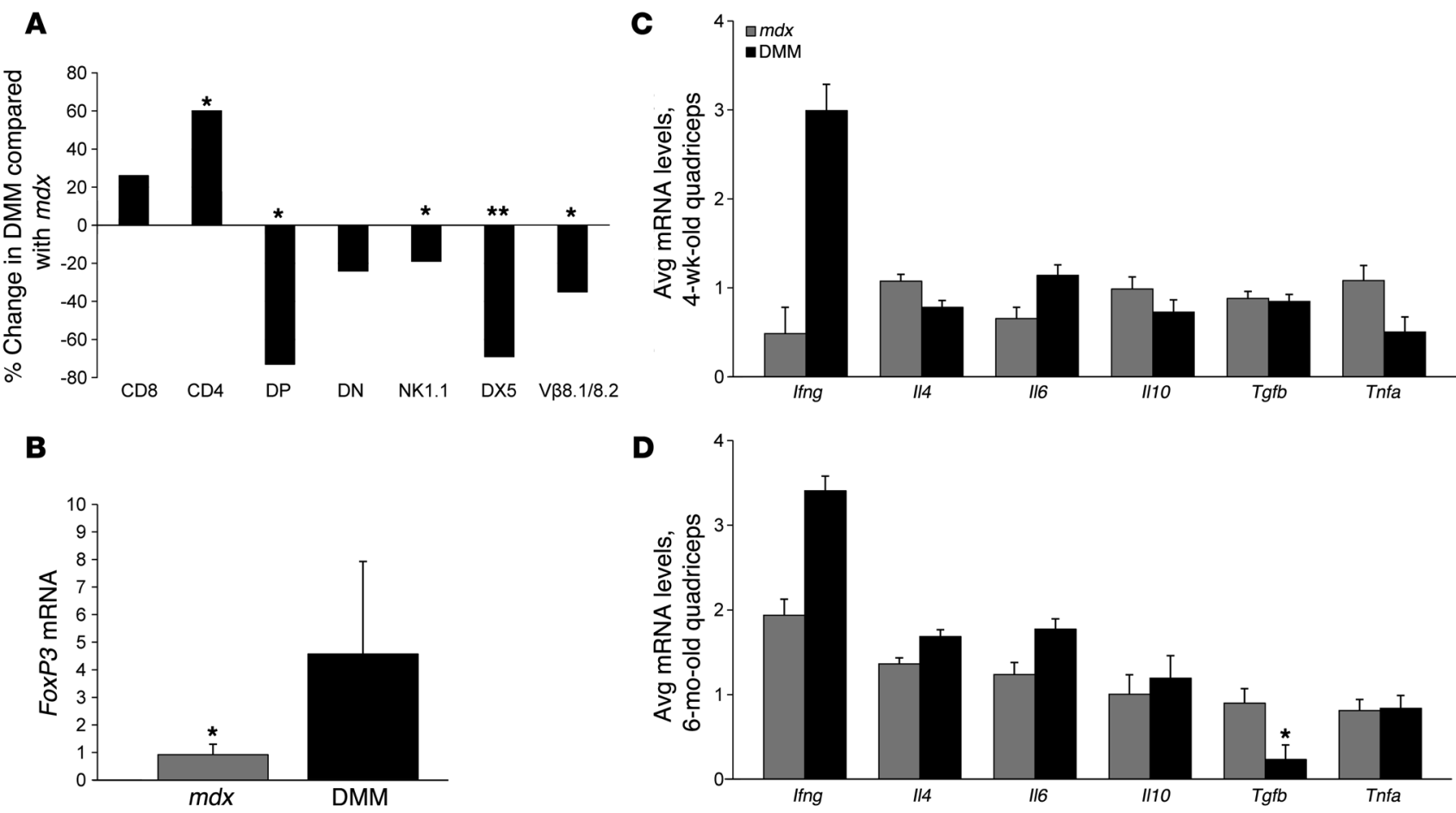

Figure 6

Lack of OPN is correlated with a reduction in TGF- $\beta$. (A) Infiltrating leukocytes isolated from $m d x$ and DMM mice were characterized by flow cytometry. Shown in the graph is the $\mathrm{CD}^{+}$population (gated from the live cell population) that was analyzed for coexpression of conventional T cell and NK cell markers. The graph shows the percentage difference of subpopulations of CD3+-infiltrating cells between DMM and $m d x$ mice, assessed from 6-8 experiments per stain. (B) QPCR analysis of 4-week-old $m d x$ and DMM quadriceps muscles, using FoxP3 primers $(n=4)$. (C and D) Cytokine mRNA expression was assessed in $m d x$ and DMM quadriceps muscles at (C) 4 weeks $(n=4)$ and (D) 6 months of age $(n=4)$ by QPCR. Expression levels for all QPCR are relative to GAPDH mRNA expression levels. Data are presented as average values. Errors bars represent SEM (B-D). ${ }^{*} P \leq 0.05 ;{ }^{* *} P \leq 0.01$.

of immune cells, we examined forkhead box P3 (FoxP3) mRNA expression in DMM and $m d x$ muscles, using QPCR. FoxP3 is a transcription factor involved in the development and function of Tregs and is a marker of these cells. This analysis showed a statistically substantial increase in FoxP 3 mRNA in DMM muscles (Figure 6B). The concomitant increase in $\mathrm{CD}^{+}$cells and elevated FoxP3 mRNA suggested that ablation of OPN induces $\mathrm{CD}^{+}$Treg infiltration (Figure 6B). Thus, OPN appears to be an immunomodulator that specifically impacts the concentration of NKT-like cells, neutrophils, and Tregs in dystrophic muscle.

DMM mice have reductions in intramuscular TGF- $\beta$ at 6 months of age. To understand the net effect of the observed inflammatory changes in 4-week-old DMM mice on the local cytokine milieu, we examined intramuscular cytokine profiles in DMM and $m d x$ mice. In comparing the concentration of numerous cytokines in DMM versus $m d x$ mice, at both 4 weeks and 6 months of age, we observed that only 1 cytokine, TGF- $\beta$, was decreased in DMM mice at 6 months of age (Figure $6, \mathrm{C}$ and D). A trend toward an increase in IFN- $\gamma$ was observed, but the data were not statistically significant. Thus, these data reveal a correlation among reductions in OPN, specific inflammatory changes, and a reduction in the profibrotic cytokine TGF- $\beta$.

Young mdx mice lacking OPN show improved muscle strength. To assess whether reductions in OPN and these inflammatory changes might alter the course of muscular dystrophy in the $m d x$ mouse, we examined DMM mice for features of disease. We first examined young mice for evidence of improvement in muscle strength and histopathology. Analysis of strength using the wire and grip strength tests showed that both 4- and 8-week-old DMM mice were stronger than age-matched $m d x$ littermates (Figure 7, A and B). Thus, a positive relationship between loss of OPN and increased muscle function was observed. Quantitative histopathology of the quadriceps did not reveal obvious differences in the amount of necrosis in the quadriceps muscles. However, the muscles of DMM and $m d x$ mice were also assayed for regenerating fibers by staining cross sections of hindlimb muscles with developmental myosin heavy chain (dMHC) (Figure 7, C and D). The number of dMHC-positive fibers was statistically increased in DMM muscles. This increased number of regenerating fibers at the first onset of pathology suggested that regeneration is improved in the absence of OPN on the dystrophic background. Future, in-depth studies will be necessary to prove this hypothesis. Thus, loss of OPN correlates with reductions in inflammation and improvements in $m d x$ muscle strength that are retained until at least 8 weeks of age.

Older mdx mice lacking OPN show reduced fibrosis in diaphragm and beart. At older than 3 months of age, $m d x$ mice no longer demonstrate significant muscular inflammation; thus, it was not surprising to find that 6 -month-old DMM mice did not retain the improvements in strength that were observed at 4 and 8 weeks of age (data not shown). Since older $m d x$ mice begin to show 

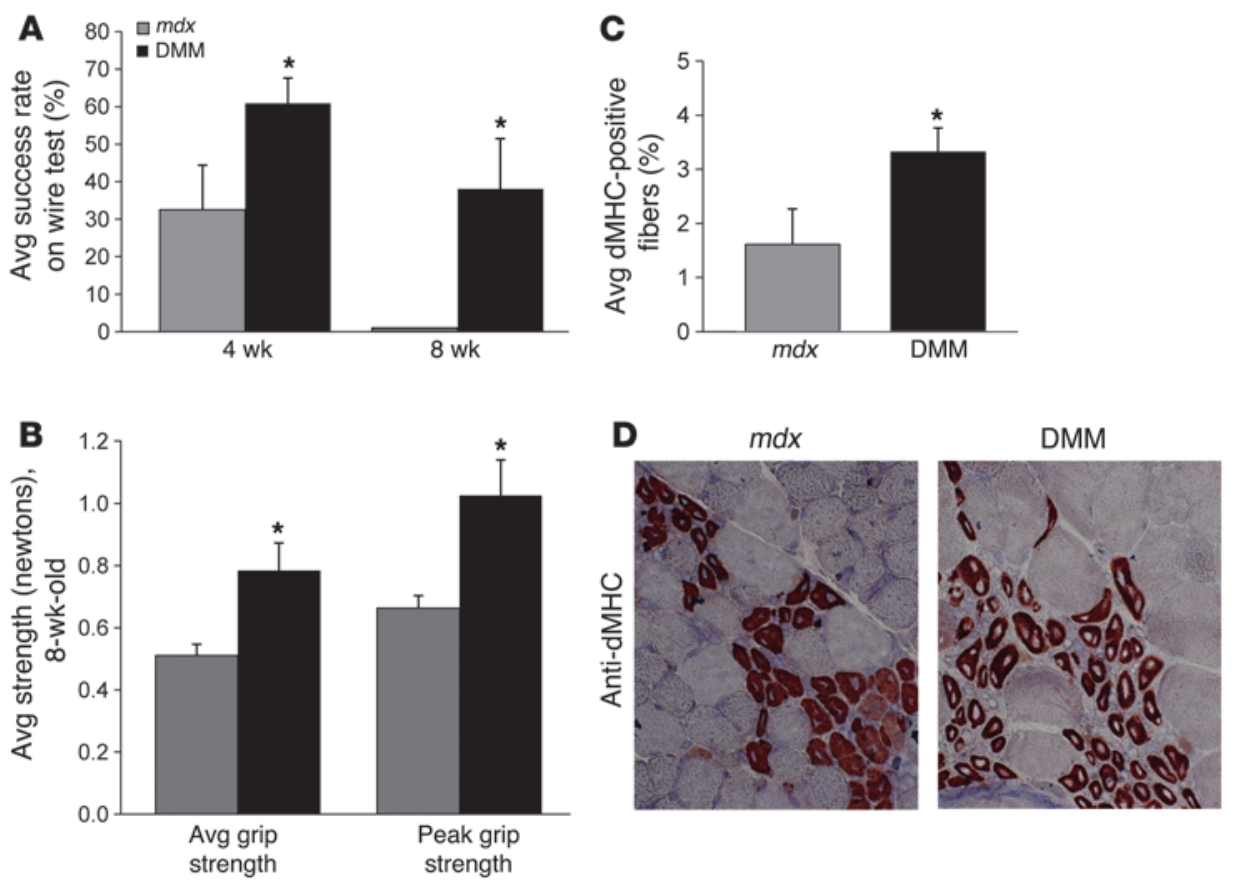

\section{Figure 7}

$m d x$ mice lacking OPN show improved muscle strength and show an increase in the number of dMHC-positive fibers at 4 weeks of age. Muscle strength was assessed in $m d x$ and DMM mice at 4 weeks ( $n=8$ and $n=24$, respectively) and 8 weeks ( $n=7$ and $n=10$, respectively) of age, using the wire and grip strength tests. (A) Graph of data obtained in the wire test. (B) Graph of data obtained in the grip strength test. Data were normalized to body weight. (C) Quadriceps muscles of $m d x$ and DMM mice were sectioned and stained with anti-mouse $\mathrm{dMHC}(n=8$ and $n=16$, respectively) at 4 weeks of age. The average number of dMHC-positive fibers was quantitated and normalized per cross-sectional area. (D) Representative sections of $m d x$ and DMM quadriceps stained for $\mathrm{dMHC}$. Original magnification, $\times 20$. Data in graphs are presented as average values. Error bars represent SEM (A-C). ${ }^{*} P \leq 0.05$, as assessed by a 2-tailed Student's $t$ test. increased fibrosis in the diaphragm and heart and because a significant link exists in the literature between inflammation and fibrosis $(18,19)$, we tested whether the reductions in inflammation observed in early stages of disease (4-8 weeks) in DMM mice translated into reduced fibrosis in later stages ( 6 months). Fibrosis was assessed using Masson's trichrome histochemical staining, Sircol collagen assay for total collagen content, and Western blots for type I collagen. These studies showed a significant reduction in fibrotic tissue accumulation in the diaphragm and hearts of DMM mice compared with age-matched controls (Figure 8). Western blot analysis demonstrated significantly less collagen type I in DMM diaphragms and hearts (Figure 8, B and C) and less total collagen as assessed by the Sircol assay (Figure 8D). These observations suggested that OPN promotes inflammation, and through its effects on the inflammatory milieu, contributes to the deposition of fibrotic tissue observed in dystrophic muscle.

\section{Discussion}

In this investigation, we characterized the infiltrating $T$ lymphocytes in $m d x$ muscle, with the goal of identifying cells that could serve as potential pharmacological targets for future studies. Cells expressing the V $\beta 8.1 / 8.2 \mathrm{TCR}$ were found to predominate over other TCR subtypes in dystrophic muscle. Further investigation of the V $\beta 8.1 / 8.2^{+}$cells showed that they secreted OPN and that elevated OPN expression in muscle and serum correlated with the disease process. Follow-up studies showed that V $\beta 8.1 / 8.2^{+}$cells were not the only source of OPN in dystrophic muscle and that other immune cells as well as muscle tissue could also produce it. Ablation of OPN resulted in a marked reduction in muscle-infiltrating neutrophils, NKT-like cells, and V $\beta 8.1 / 8.2^{+}$cells. Thus, OPN attracts certain immune cell subtypes to dystrophic muscle. Ablation of OPN also caused an increase in intramuscular Tregs. These inflammatory changes resulted in a net reduction in TGF- $\beta$ and fibrosis.

$O P N$ and disease. Several studies have demonstrated that OPN is highly inducible in disease states. For example, OPN was highly expressed in white matter adjacent to plaques in brains from patients with MS as well as in the brains from EAE and Lewis rat models of MS (44). Furthermore, studies with the OPN-knockout mouse and/or blocking antibodies have elucidated its role in promotion of diseases such as in rheumatoid arthritis (24), concanavalin A-induced liver disease (45), and EAE. In the case of EAE, the improved disease in the OPN-knockout mouse was due to reduced survival of autoreactive T cells (23). OPN promotes tumor metastases in several different hematopoietic cancers, including multiple myeloma and chronic myelogenous leukemia (46). Its participation in these cancers has been attributed to several characteristics of OPN, including its presence in bone near the hematopoietic compartment, and its promigratory and proangiogenic properties (46). Thus, while OPN appears to be widely expressed, its levels are highly upregulated in response to disease states, such as in the case of DMD muscle. This feature of upregulation may make OPN an ideal therapeutic target, since its expression is elevated specifically in the affected tissue to be targeted.

$O P N$ and muscle. The relationship between OPN and skeletal muscle is not fully understood. In vitro studies have shown that skeletal muscle-derived cells can produce OPN $(47,48)$. In particular, a recent in vitro study showed that myoblasts and myotubes from C2C12 cells and primary C57BL/ 6 myoblast cultures synthesize OPN in response to cytokines such as IL- $1 \beta$ and TGF- $\beta$ (49). In agreement with our findings, they also found OPN expression to be low during the prenecrotic stage of $m d x$ disease and increased during the necrotic/regenerative stage. These observations suggest that the elevation of OPN in dystrophic muscle occurs in response to the inflammatory environment of the muscle. While one study identified OPN to be highly upregulated (by microarray analysis) in cardiotoxin-injured muscle, the authors concluded that the source of the OPN in the microarrays was infiltrating immune cells (42). OPN has been reported to be expressed by cardiomyocytes (50), although this point is controversial (51), and its expression increases in models of experimental autoimmune myocarditis 
A

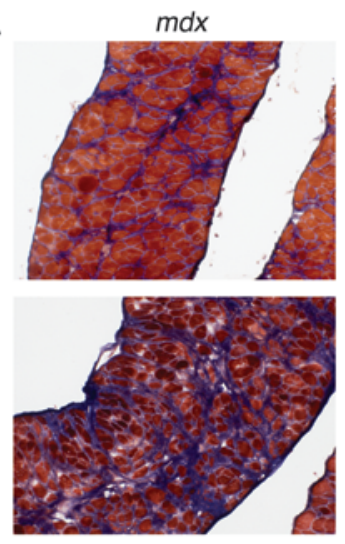

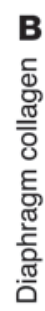
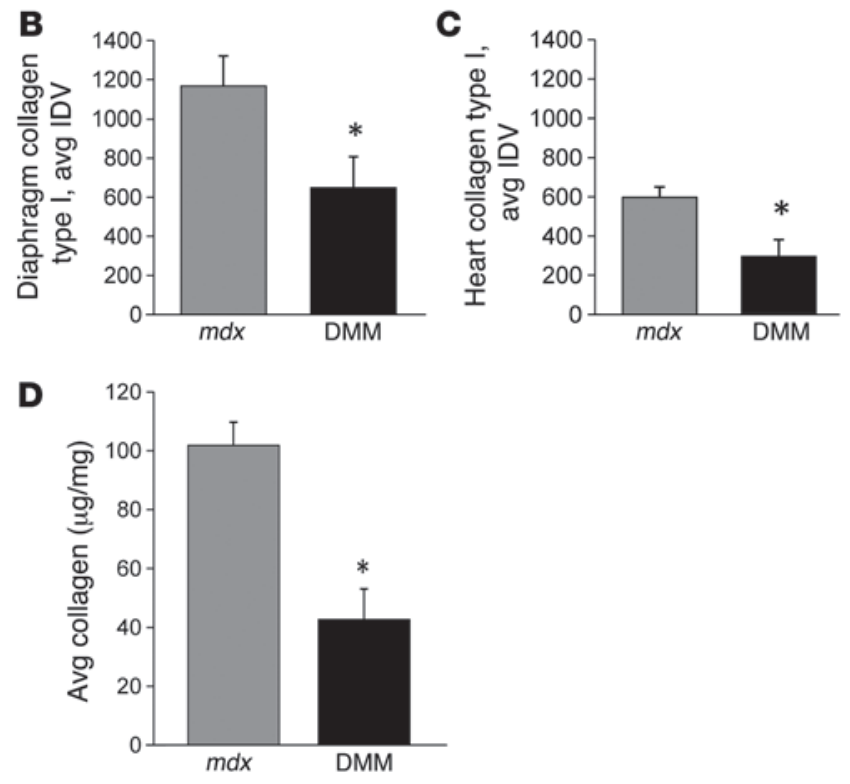

(50). Thus, OPN appears to increase in cardiac and skeletal muscle following cellular stress or injury.

$O P N$ and regeneration. Pagel and colleagues found a positive relationship between OPN and muscle regeneration in vitro (49), as would be expected, due to the ability of OPN to bind CD44 on myoblasts (52). Conversely, we observed that loss of OPN correlated with increased $\mathrm{dMHC}$-positive fibers. It is possible that because OPN has such diverse effects on many different cell types, our observation of increased muscle regeneration in vivo is indirectly related to the absence of OPN. Alternatively, concentrations of OPN in vivo may be much lower than those used in the previous in vitro studies. Regardless, the current study suggests that the net effect of loss of OPN in vivo is positive for regeneration; however, in-depth studies need to be carried out to truly address this issue. Another possible explanation for the increase in dMHC-positive fibers is that necrosis is worse immediately preceding the 4-week analysis point. The data do not support this conclusion, since (a) the mice are stronger at 4 weeks of age and (b) the histopathology of the cross sections did not reveal an increase in necrosis. Thus, while the possibility that necrosis is worse in the absence of OPN is a possibility that needs to be taken into account, the likelihood that this scenario is taking place is low. These studies point out the necessity of future preclinical studies that would target

\section{Figure 8}

Ablation of OPN correlates with reductions in diaphragm and cardiac fibrosis. (A) Micrographs show representative trichrome staining of diaphragms from $m d x$ (left panels) and DMM (right panels) animals. The top 2 panels are of 6 -month-old mice, whereas bottom 2 panels are of 7-month-old mice. Areas of blue staining indicate proliferation of ECM (i.e., fibrosis), and areas of red staining indicate muscle tissue. Original magnification, $\times 20$. (B) Graph of densitometry of collagen type I Western blots assessed in 6-month-old diaphragms $(n=5-7)$ and (C) 1 -year-old hearts $(n=6-7)$. IDV, integrated density value. (D) Total collagen was assessed biochemically in 6-month-old diaphragms using the Sircol collagen assay $(n=6-7)$. Error bars show SEM (B-D). ${ }^{*} P \leq 0.05$, as assessed by a 2 -tailed Student's $t$ test.

OPN therapeutically to monitor the effect of drug intervention on muscle repair.

What is the source of elevated OPN in dystrophic muscle? Numerous types of inflammatory cells express OPN, including $\mathrm{T}$ cells (our observations), neutrophils (33), and macrophages (50). Furthermore, muscle cells also produce OPN. One possible scenario for the appearance of elevated OPN levels in dystrophic muscle is the following. The data in this investigation support the hypothesis that the initial invading immune cells are the first source of OPN. Once they have entered the muscle, they could secrete OPN, thus triggering further OPN secretion from skeletal muscle. This hypothesis is supported by the observation that elevated OPN levels are observed after the initial bout of inflammation in $m d x$ dystrophy. In the current study, increased expression of OPN in DMD biopsies was observed in immune cells and in the cytoplasm of muscle fibers adjacent to necrotic areas. This increase in muscle OPN may also derive from fibers experiencing an increase in mechanical loading (i.e., stress) due to their proximity to weakened, necrotic areas that are not able to bear loads. Studies using a chronic pressure overload model have shown that OPN increases in the heart during myocardial hypertrophy (53). In addition, previous studies have shown that osteocytes deprived of oxygen express elevated levels of OPN (54). In dystrophic muscle, the stresses of both hypoxia and increased muscle loading on "healthy" fibers could feasibly trigger the increased muscular expression of OPN that was observed in this study. Cleavage of OPN by thrombin results in the exposure of 2 additional cryptic sites that bind with high affinity to integrins $\alpha 9 \beta 1$ and $\alpha 4 \beta 1$ (24), the latter of which is expressed by differentiated muscle cells. Thus, while the highly elevated OPN in dystrophic muscle is clearly due to the inflammation and loss of load-bearing capability, the role of OPN in normal muscle might be to facilitate sarcolemmal adhesion to the ECM.

OPN is likely to be modulating the course of fibrosis in muscular dystrophy through its chemotactic and proinflammatory properties. OPN binds to the integrin CD44, a protein that is expressed on the surface of some immune cells $(1,32,55)$. Our previous results demonstrated that CD $44^{\text {high }}$ is highly expressed in leukocytes extracted from dystrophic muscle compared with normal mice and with splenocytes from dystrophic animals (1). Thus, infiltrating immune cells from $m d x$ mice are already "primed" to bind to OPN. Furthermore, previous studies have shown that OPN binding to CD44 on NKT cells can elicit increased cytokine secretion and enable their resistance to activation induced cell death (55). This mechanism might explain the reduction in NKTlike cells observed in the DMM muscles. These studies are also the first to show a relationship between OPN and Tregs and also 
between Tregs and muscular dystrophy. These relationships will need further investigation before their role in the disease process is completely understood.

$O P N$, neutrophils, and TGF- $\beta$. A reciprocal relationship between neutrophils and OPN was observed in this study. It was previously shown that neutrophils can produce OPN and that OPN is chemotactic for neutrophils in a CD44-independent manner (33). It is possible that the reduction in neutrophils observed in the DMM muscle is responsible for the concomitant reduction in TGF- $\beta$. While neutrophils can directly produce OPN, they can also influence TGF- $\beta$ production by other cell types. For example, neutrophils can release elastase, which has been shown to activate immature DCs and induce them to produce TGF- $\beta$ (56). In vitro studies have also shown that neutrophils can release ectosomes that interfere with the phagocytic ability of DCs, while promoting their production and release of TGF- $\beta$ (57). Furthermore, macrophages that phagocytose neutrophils can also produce TGF- $\beta$ (58, $59)$. Thus, neutrophils can modulate levels of TGF- $\beta$ through a variety of mechanisms.

A positive relationship between TGF- $\beta$ and muscle fibrosis has been demonstrated repeatedly in the muscular dystrophy literature, in which it has been shown that reductions in TGF- $\beta$ correlate with reductions in diaphragm fibrosis $(60,61)$. In this investigation, we reveal what we believe to be a novel regulator of TGF- $\beta$ levels in dystrophic muscle called OPN. Ablation of OPN impacted inflammation and correlated with reduced fibrosis. OPN not only regulates intramuscular immune cell concentrations but might also regulate secretion of matrix factors by myofibroblasts (62). Future studies should be designed to identify methods to pharmacologically reduce OPN in muscle tissue and to better understand the relationship between OPN, Tregs, and the dystrophic process.

\section{Methods}

Animals. C57BL/6, $m d x(\mathrm{C} 57 \mathrm{BL} / 10 \mathrm{ScSn}-m d x / \mathrm{J})$, and OPN-knockout mice (B6.Cg-Spp $1^{\mathrm{tm} 1 \mathrm{Blh}} / \mathrm{J}$ ) were obtained from The Jackson Laboratory. The OPNknockout mouse was created by replacing exons 4-7 with the phosphoglycerate kinase neomycin resistance cassette (31). To create the DMM mice, male OPN-knockout mice were crossed with homozygous $m d x$ females (on the $\mathrm{C} 57 \mathrm{BL} / 10$ background) to produce mice that were heterozygotes for the targeted mutation in OPN and hemizygous (male) or heterozygous (female) for the dystrophin mutation (on the X chromosome). Female and male F1 progeny were crossed to create DMM mice lacking both OPN and dystrophin and $m d x$ littermate controls. Mice were screened for the OPN-knockout cassette according to Liaw et al. (31), while the point mutation in exon 23 of the $m d x$ mouse was identified by $m d x$-amplification-resistant mutation system assay (ARMS PCR) (63). All mice were housed and bred in the UCLA vivarium, according to regulations stipulated by the Department of Laboratory and Animal Medicine. Procedures for animal use, euthanasia, and care were approved by the UCLA Office of Protection of Research Subjects.

QPCR. RNA was isolated from cells or frozen tissue using TrizoL (Invitrogen), treated with DNase I (Invitrogen), and transcribed with SuperScript III (Invitrogen). All PCR reactions were carried out using iQ SYBR Green Supermix (Bio-Rad) for 40-50 cycles, with a melting temperature of $94^{\circ} \mathrm{C}$ for 30 seconds, an annealing temperature of $58^{\circ} \mathrm{C}-60^{\circ} \mathrm{C}$ for 30 seconds, and an extension temperature of $72^{\circ} \mathrm{C}$ for 30 seconds. The following primer pairs were used (all shown $5^{\prime}-3^{\prime}$ ): GAPDH (forward), ACTCCACTCACGGCAAATTC, (reverse), TCTCCATGGTGGTGAAGACA; V $\beta 8.2$ (forward), GAGGCTGCAGTCACCCAAAGCCCAAG; C $\beta A$ (constant region-reverse primer for V $\beta 8.2$ PCR), CCAGAAGGTAGCAGAGACCC; OPN (forward), GATGATGATGACGATGGAGACC, (reverse), CGACT-
GTAGGGACGATTGGAG; IFN- $\gamma$ (forward), GCTTTGCAGCTCTTCCTCAT, (reverse), GTCACCATCCTTTTGCCAGT; IL-4 (forward), CTCACAGAGAGAAGACTCTGTGCACCGAG, (reverse), CACAGGACAGGAATTCAAGCCCGCCAGGC; IL-6 (forward), AGTTGCCTTCTTGGGACTGA, (reverse), TCCACGATTTCCCAGAGAAC; IL-10 (forward), CCAAGCCTTATCGGAAATGA, (reverse), TTTTCACAGGGGAGAAATCG; TGF- $\beta$ (forward), TGCGCTTGCAGAGATTAAAA, (reverse), CGTCAAAAGACAGCCACTCA; TNF- $\alpha$ (forward), CCCCAAAGGGATGAGAAGTT, (reverse), CACTTGGTGGTTTGCTACGA; FoxP3 (forward), ACCACACTTCATGCATCAGC, (reverse), ACTTGGAGCACAGGGGTCT.

ELISPOT assay. ELISPOT plates (Millipore) were coated with capture antibodies (anti-mouse IFN- $\gamma$, IL-2, IL-4, IL-6, IL-10, IL-12, and TNF- $\alpha$; BD Bioscience) diluted in coating buffer (1:200, sterile $1 \mathrm{X}$ Dulbecco's PBS [DPBS]) and incubated overnight at $4{ }^{\circ} \mathrm{C}$. After incubation, plates were washed twice with blocking solution (sterile RPMI 1640, 10\% fetal bovine serum, $1 \%$ penicillin-streptomycin, L-glutamine) and incubated for 2 hours at room temperature with blocking solution. Splenocytes $\left(3 \times 10^{5}\right.$ cells/well) were suspended in complete media and added to the plates and incubated overnight at $37^{\circ} \mathrm{C}$. Plates were washed twice with distilled water, washed 2 more times with Wash Buffer I (1X DPBS with 0.05\% Tween 20), and then incubated in detection antibodies (diluted 1:250 in dilution buffer; BD Bioscience) for 2 hours at room temperature. Plates were washed 3 times with Wash Buffer I, followed by the addition of streptavidin-horseradish peroxidase for ELISPOT (diluted at 1:100 in dilution buffer), and incubated at room temperature for 1 hour. Plates were washed 4 times with Wash Buffer II (1X DPBS), followed by the addition of Detection Substrate for ELISPOT (prepared according to manufacture instructions; BD Bioscience), and incubated at room temperature in the dark. Spot development was monitored for the next 5-40 minutes, and the substrate reaction was stopped by washing plates with distilled water. Plates were left to dry overnight in the dark and analyzed at the UCLA Immuno/BioSpot Core using the ImmunoSpot Series 1 Analyzer (C.T.L.) and then analyzed with ImmunoSpot 4.0 Professional analysis software (C.T.L.).

Isolation of muscle lenkocytes. Muscles were collected and washed with DPBS without $\mathrm{Ca}^{+}$and $\mathrm{Mg}^{+}$(Invitrogen). Muscles were minced in $10 \mathrm{ml}$ of collagenase solution $(0.5 \mathrm{mg} / \mathrm{ml}$ Type IA collagenase, $0.5 \mathrm{mg} / \mathrm{ml}$ Type IV collagenase in complete RPMI media; Invitrogen) and incubated at $37^{\circ} \mathrm{C}$ for 45 minutes. Following incubation, muscles were transferred into a $50 \mathrm{ml}$ conical tube and triturated vigorously until the muscle suspension could pass easily through a $25 \mathrm{ml}$ pipet. The suspension was then equally aliquoted into four $50 \mathrm{ml}$ conical tubes, each brought up to $40 \mathrm{ml}$ with DPBS and left to settle at room temperature for 5 minutes. The top liquid layer of each tube was transferred into a new $50 \mathrm{ml}$ conical tube and left to settle for another 5 minutes at room temperature. The top liquid layers were then filtered through a $70 \mu \mathrm{m}$ basket into new $50 \mathrm{ml}$ conical tubes, brought up to $40 \mathrm{ml}$ with DPBS, and centrifuged at $670 \mathrm{~g}$ for 10 minutes at room temperature. Pellets were resuspended in $15 \mathrm{ml}$ of DPBS, layered on $15 \mathrm{ml}$ of Lympholyte-M (Cedarlane Laboratories), and centrifuged at 2,095 g for 45 minutes at room temperature. Cells at the interface of each sample were collected and centrifuged at $965 \mathrm{~g}$ for 10 minutes at room temperature and resuspended in PBS. These preparations yielded approximately $1 \times 10^{6}$ to $2 \times 10^{6}$ highly purified leukocytes per 4 mice.

Flow cytometry. For flow cytometry of $m d x$ leukocytes, 100,000 cells were used for each stain. Prior to staining, $m d x$ leukocyte suspensions were incubated with anti-CD16/CD32 (FcrRII/III, clone 2.4G2; BD Bioscience - Pharmingen) to block nonspecific binding to Fc receptors. The following mouse monoclonal antibodies used for staining were all obtained from BD Bioscience - Pharmingen: CD3e (clone 145-2C11), CD4 (clone RM4-5), CD8 $\alpha$ (clone 53-6.7), TCR- $\beta$ (clone H57-597), V $\beta 2$ (clone H57-597), V $\beta 3$ (clone KJ25), V $\beta 5.1 / 5.2$ (clone MR9-4), V $\beta 8.1 / 8.2$ (clone MR5-2), V $\beta 8.3$ 
(clone 1B3.3), V $\beta 10 \mathrm{~b}$ (clone B21.5), V $\beta 11$ (clone RR3-15), V $\beta 14$ (clone 14-2), NK-1.1 (clone PK136), pan NK (clone DX5), CD49d ( $\alpha 4$ integrin, clone R1-2), CD106 (VCAM-1, clone 429), and CD134 (OX-40, clone OX-86). The following mouse mAbs were obtained from eBioscience: CD2 (clone RM2-5), CD28 (clone 37.51), CD154 (gP39, clone MR1), CD152 (CTLA-4, clone 9H10), CD69 (clone H1.2F3), CD45R (B220, clone RA3-6B2), F4/80 (clone $\mathrm{BM} 8$ ), and Ly6G (clone RB6-8C5). Other mouse mAbs were CD68 (clone FA-11; AbD Serotec) and CD206 (clone MR5D3; AbD Serotec). Antibodies were conjugated to FITC, PE, Cy5, or biotin. For cells stained with biotinylated antibodies, Tri/Color-conjugated streptavidin (eBioscience) was added. Optimal working dilutions were determined for each antibody prior to use. All incubations were performed in $\mathrm{Ca}^{+}, \mathrm{Mg}^{+}$-free DPBS (Invitrogen) at $4^{\circ} \mathrm{C}$ for 30 minutes. Following the last wash, $10^{4}$ live cells per sample were acquired on a FACSCalibur (Becton Dickinson) and analyzed with CELLQuest Pro software (Becton Dickinson).

Differentiation of Th cells for use as controls for quantitative PCR. Splenocytes from 5C.C7 TCR transgenic mice were stimulated with $1 \mu \mathrm{M}$ of pigeon cytochrome $\mathrm{C}$ protein, residues $88-104$, under Th1-differentiating condi-

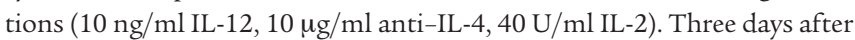
primary stimulation, cultures were expanded with complete RPMI supplemented with $20 \mathrm{U} / \mathrm{ml} \mathrm{IL-2}$. One week after primary stimulation, cells were washed and equal numbers were restimulated with plate-bound anti-CD3 $(1 \mathrm{mg} / \mathrm{ml})$ and soluble anti-CD28 $(5 \mathrm{mg} / \mathrm{ml})$ under differentiating conditions. Cells were expanded and maintained with complete RPMI supplemented with $20 \mathrm{U} / \mathrm{ml} \mathrm{IL-2}$. After treatment, more than $97 \%$ of cells were $\mathrm{CD} 4^{+} \mathrm{IL}-4^{+}$. Restimulated differentiated cells were first rested for $2-3$ days in complete RPMI without IL-2. These cells were used as controls for Opn mRNA for quantitative PCR experiments.

Immunohistochemistry. Muscles were dissected, placed on balsa wood, coated with Tissue-Tek OCT mounting media (Sakura Finetek), and frozen in isopentane cooled by liquid nitrogen. Diaphragm muscles were cut in half down the midline and rolled before freezing. Ten-micron sections were cut on a Micron HM 505E cryostat (Micron Instruments Inc.) and stored at $-20^{\circ} \mathrm{C}$ until use. Immunohistochemistry was performed as previously described (64).

Histopathology index. To quantitatively assess histopathology, muscle sections were stained with anti-CD11b (clone M1/70; BD Biosciences) to emphasize necrotic areas and $\mathrm{dMHC}$ (clone RNMy2/9D2; Novocastra) to emphasize regenerating fibers. A mosaic photograph was then taken of each cross section using an AXIO Imager MI Zeiss Microscope and analyzed with AxioVision software (Zeiss). Necrotic or regenerating areas were demarcated using the software, and data were normalized per total crosssectional area. All analyses were performed blindly.

Wire test. Mice were tested for grip strength using a wire apparatus suspended 2 feet from the base. The wire test was made up of 5 trials, with each trial consisting of a hanging period of 1 minute followed by a rest period of 1 minute. The hanging time was recorded for each trial. The percentage of success was determined as the fraction of the 5 trials in which the mouse was able to successfully hold on for a full 60 seconds.

Forelimb grip strength test. Forelimb grip strength was measured using a digital force gauge (DFIS 2, Chatillon CE). In each trial, the mouse was allowed to grasp a metal rod and the technician slowly pulled the mouse by the tail until the digital gauge recorded the peak tension (in Newtons) produced. Five trials were performed with a minimum of 30 seconds rest in between. Upon completion of the grip strength test, the body weight was recorded. For analysis, peak tension produced in all 5 trials was averaged and normalized for body weight.

OPNELISA assay. Serum OPN concentration was analyzed by solid-phase sandwich ELISA using a Mouse Osteopontin Assay kit (Immuno-Biological Laboratories Inc.) according to the manufacturer's specifications.
Human biopsies and microarrays. Flash-frozen muscle biopsies were received by the Research Center for Genetic Medicine, Children's National Medical Center for diagnostic purposes. Informed consent was obtained for the biopsies. After diagnosis, samples were anonymized and sent to UCLA for histological analyses. DMD biopsies showed histopathology consistent with a severe dystrophic myopathy and showed complete dystrophin deficiency by both immunostaining (carboxyl terminal antibodies) and immunoblot (rod domain antibodies) procedures. Normal controls were referred for molecular diagnostics but showed normal histology and normal biochemical studies.

mRNA profiling data sets used here were previously published $(36,37)$ and included 13 diagnostic groups, with a total of 125 muscle biopsies tested on both Affymetrix U133A and U133B microarrays (250 microarrays total). To query this data set, we used a publicly accessible SAS server with box plot visualizations (http://pepr.cnmcresearch.org and http://www. ncbi.nih.gov/geo).

Human subjects. All experiments using materials from human subjects were reviewed and approved by the Children's National Medical Center Institutional Review Board.

Sircol collagen assay. Total collagen (collagens type I-V) content was assessed in 6-month-old mouse diaphragms, using the Sircol Soluble Collagen Assay kit (Accurate Scientific) according to the manufacturer's specifications. Briefly, mouse diaphragms were homogenized in 7 volumes of Complete Buffer (Roche) to wet-weight of tissue, sonicated for 30 seconds, and centrifuged at $10,000 \mathrm{~g}$ for 10 minutes. Supernatants were filtered through a $1.2 \mu \mathrm{m}$ syringe filter, and $50 \mu \mathrm{l}$ of each sample was transferred to a new tube. Each sample received $50 \mu \mathrm{l}$ of $0.5 \mathrm{M}$ acetic acid and was mixed by gentle inversion. Then, $1.0 \mathrm{ml}$ Sircol Dye Reagent was added and gently mixed for 30 minutes at room temperature. Samples were then centrifuged at $10,000 \mathrm{~g}$ for 10 minutes, the supernatant was discarded, and $1.0 \mathrm{ml}$ of Sircol Alkali Reagent was then added to each sample and gently mixed until precipitates dissolved completely. Then, $100 \mu \mathrm{l}$ of each sample was transferred to a 96-well ELISA plate, and absorbance was read at $540 \mathrm{~nm}$ using a Multiskan plate reader (Thermo Fisher Scientific).

Western blots. Muscle samples were homogenized in 40 volumes of reducing sample buffer (100 mM DTT, 2\% SDS, $0.08 \mathrm{M}$ Tris, $10 \%$ glycerol) with protease inhibitors (P-8340; Sigma-Aldrich) and analyzed by Western blotting as previously described (64). Blots were probed with anti-collagen type I (diluted 1:100, Cedarlane Laboratories) and analyzed by densitometry.

Statistics. For all proposed experiments and procedures, a multiple comparison, 1-way ANOVA was used for experiments involving more than 2 groups. Two-tailed Student's $t$ test or Mann-Whitney $U$ test were used for experiments using only 2 groups. All $t$ tests were 2 tailed. Values were considered significantly different if $P$ was less than 0.05 . For ELISPOT and QPCR analysis, means were compared using the ANOVA model, with treatment group as fixed effect and plate as random effect. The inclusion of a random plate effect takes into account the correlation of observations within a single plate. Prior to the analysis, the data were $\log 10$ transformed, as $\log$ transformed data better approximate a normal distribution. The results are summarized in the form of geometric means. $\log 10(0)$ is undefined and 0 values are substituted by one-half the minimum observed value for the purpose of analysis.

\section{Acknowledgments}

This study was supported by funds from the National Institutes of Health (National Institute of Arthritis and Musculoskeletal and Skin Diseases [NIAMS]) RO1-AR046911 (to M.J. Spencer), Parent Project for Muscular Dystrophy (to M.J. Spencer), and the Department of Defense (to C.M. Miceli). S.A. Vetrone was 
supported in part by award number T32 GM065823 from the National Institutes of General Medical Science. Flow cytometry was carried out on equipment supported by the UCLA DMD Center and maintained and housed by the Department of Microbiology, Immunology, and Molecular Genetics at UCLA. ELISPOT was performed at the UCLA Immuno/BioSpot Core. The authors thank Jane Wen, Leonel Martinez, and Jose Morales for excellent technical assistance.
Received for publication October 6, 2008, and accepted in revised form April 1, 2009.

Address correspondence to: Melissa J. Spencer, Department of Neurology, UCLA, 635 Charles E. Young Dr. South, Neuroscience Research Building - Room 401, Los Angeles, California 900957334, USA. Phone: (310) 794-5225; Fax: (310) 206-1998; E-mail: mspencer@mednet.ucla.edu.
1. Spencer, M.J., Montecino-Rodriguez, E., Dorshkind, K., and Tidball, J.G. 2001. Helper $\left(\mathrm{CD} 4\left(^{+}\right)\right)$ and cytotoxic $\left(\mathrm{CD} 8\left(^{+}\right)\right) \mathrm{T}$ cells promote the pathology of dystrophin-deficient muscle. Clin. Immunol. 98:235-243.

2. Wehling, M., Spencer, M.J., and Tidball, J.G. 2001. A nitric oxide synthase transgene ameliorates muscular dystrophy in mdx mice. J. Cell Biol. 155:123-131.

3. Hodgetts, S., Radley, H., Davies, M., and Grounds, M.D. 2006. Reduced necrosis of dystrophic muscle by depletion of host neutrophils, or blocking TNFalpha function with Etanercept in mdx mice. Neuromuscul. Disord. 16:591-602.

4. Gorospe, J.R., Tharp, M., Demitsu, T., and Hoffman, E.P. 1994. Dystrophin-deficient myofibers are vulnerable to mast cell granule-induced necrosis. Neuromuscul. Disord. 4:325-333.

5. Cai, B., Spencer, M.J., Nakamura, G., Tseng-Ong, L., and Tidball, J.G. 2000. Eosinophilia of dystrophindeficient muscle is promoted by perforin-mediated cytotoxicity by $\mathrm{T}$ cell effectors. Am. J. Pathol. 156:1789-1796.

6. Wehling-Henricks, M., et al. 2008. Major basic protein-1 promotes fibrosis of dystrophic muscle and attenuates the cellular immune response in muscular dystrophy. Hum. Mol. Genet. 17:2280-2292.

7. Chen, Y.W., et al. 2005. Early onset of inflammation and later involvement of TGFbeta in Duchenne muscular dystrophy. Neurology. 65:826-834.

8. Spencer, M.J., Lu, B., and Tidball, J.G. 1997. Calpain II expression is increased by changes in mechanical loading of muscle in vivo. J. Cell. Biochem. 64:55-66.

9. Wehling-Henricks, M., Lee, J.J., and Tidball, J.G. 2004. Prednisolone decreases cellular adhesion molecules required for inflammatory cell infiltration in dystrophin-deficient skeletal muscle. New romuscul. Disord. 14:483-490.

10. Spencer, M.J., Walsh, C.M., Dorshkind, K.A., Rodriguez, E.M., and Tidball, J.G. 1997. Myonuclear apoptosis in dystrophic mdx muscle occurs by perforinmediated cytotoxicity. J. Clin. Invest. 99:2745-2751.

11. Gosselin, L.E., Barkley, J.E., Spencer, M.J., McCormick, K.M., and Farkas, G.A. 2003. Ventilatory dysfunction in mdx mice: impact of tumor necrosis factor-alpha deletion. Muscle Nerve. 28:336-343.

12. Gosselin, L.E., and Martinez, D.A. 2004. Impact of TNF-alpha blockade on TGF-beta1 and type I collagen mRNA expression in dystrophic muscle. Muscle Nerve. 30:244-246.

13. Radley, H.G., Davies, M.J., and Grounds, M.D. 2008. Reduced muscle necrosis and long-term benefits in dystrophic mdx mice after cV1q (blockade of TNF) treatment. Neuromuscul. Disord. 18:227-238.

14. De Luca, A., et al. 2005. A multidisciplinary evaluation of the effectiveness of cyclosporine a in dystrophic mdx mice. Am. J. Pathol. 166:477-489.

15. Pierno, S., et al. 2007. Role of tumour necrosis factor alpha, but not of cyclo-oxygenase-2-derived eicosanoids, on functional and morphological indices of dystrophic progression in mdx mice: a pharmacological approach. Neuropathol. Appl. Neurobiol. 33:344-359.

16. Alexakis, C., Partridge, T., and Bou-Gharios, G. 2007. Implication of the satellite cell in dystrophic muscle fibrosis: a self-perpetuating mechanism of collagen overproduction. Am. J. Physiol. Cell Physiol. 293:C661-C669.
17. Bernasconi, P., et al. 1999. Transforming growth factor-beta 1 and fibrosis in congenital muscular dystrophies. Neuromuscul. Disord. 9:28-33.

18. Morrison, J., Lu, Q.L., Pastoret, C., Partridge, T., and Bou-Gharios, G. 2000. T-cell-dependent fibrosis in the $\mathrm{mdx}$ dystrophic mouse. Lab. Invest. 80:881-891.

19. Farini, A., et al. 2007. T and B lymphocyte depletion has a marked effect on the fibrosis of dystrophic skeletal muscles in the scid/mdx mouse. J. Pathol. 213:229-238.

20. Bayless, K.J., Meininger, G.A., Scholtz, J.M., and Davis, G.E. 1998. Osteopontin is a ligand for the alpha4beta1 integrin. J. Cell Sci. 111:1165-1174.

21. Barry, S.T., Ludbrook, S.B., Murrison, E., and Horgan, C.M. 2000. Analysis of the alpha4beta 1 integrin-osteopontin interaction. Exp. Cell Res. 258:342-351.

22. Barry, S.T., Ludbrook, S.B., Murrison, E., and Horgan, C.M. 2000. A regulated interaction between alpha5beta1 integrin and osteopontin. Biochem. Biophys. Res. Commun. 267:764-769.

23. Hur, E.M., et al. 2007. Osteopontin-induced relapse and progression of autoimmune brain disease through enhanced survival of activated T cells. Nat. Immunol. 8:74-83.

24. Yamamoto, N., et al. 2003. Essential role of the cryptic epitope SLAYGLR within osteopontin in a murine model of rheumatoid arthritis. J. Clin. Invest. 112:181-188.

25. Katagiri, Y.U., et al. 1999. CD44 variants but not CD44s cooperate with beta1-containing integrins to permit cells to bind to osteopontin independently of arginine-glycine-aspartic acid, thereby stimulating cell motility and chemotaxis. Cancer Res. 59:219-226.

26. Mukherjee, B.B., et al. 1995. Interaction of osteopontin with fibronectin and other extracellular matrix molecules. Ann. N. Y. Acad. Sci. 760:201-212.

27. Yoshitake, H., Rittling, S.R., Denhardt, D.T., and Noda, M. 1999. Osteopontin-deficient mice are resistant to ovariectomy-induced bone resorption. Proc. Natl. Acad. Sci. U. S. A. 96:8156-8160.

28. Asou, Y., et al. 2001. Osteopontin facilitates angiogenesis, accumulation of osteoclasts, and resorption in ectopic bone. Endocrinology. 142:1325-1332.

29. Petrik, D., et al. 2006. Plasma osteopontin is an independent prognostic marker for head and neck cancers. J. Clin. Oncol. 24:5291-5297.

30. Khodavirdi, A.C., et al. 2006. Increased expression of osteopontin contributes to the progression of prostate cancer. Cancer Res. 66:883-888.

31. Liaw, L., et al. 1998. Altered wound healing in mice lacking a functional osteopontin gene (spp1). J. Clin. Invest. 101:1468-1478.

32. Zhu, B., et al. 2004. Osteopontin modulates CD44dependent chemotaxis of peritoneal macrophages through G-protein-coupled receptors: evidence of a role for an intracellular form of osteopontin. J. Cell. Physiol. 198:155-167.

33. Koh, A., et al. 2007. Role of osteopontin in neutrophil function. Immunology. 122:466-475.

34. Gussoni, E., et al. 1994. Specific T cell receptor gene rearrangements at the site of muscle degeneration in Duchenne muscular dystrophy. J. Immunol. 153:4798-4805.

35. Kissel, J.T., Burrow, K.L., Rammohan, K.W., and
Mendell, J.R. 1991. Mononuclear cell analysis of muscle biopsies in prednisone-treated and untreated Duchenne muscular dystrophy. CIDD Study Group. Neurology. 41:667-672.

36. Bakay, M., Zhao, P., Chen, J., and Hoffman, E.P. 2002. A web-accessible complete transcriptome of normal human and DMD muscle. Neuromuscul. Disord. 12(Suppl. 1):S125-S141.

37. Bakay, M., et al. 2006. Nuclear envelope dystrophies show a transcriptional fingerprint suggesting disruption of Rb-MyoD pathways in muscle regeneration. Brain. 129:996-1013.

38. Chen, Y.W., Zhao, P., Borup, R., and Hoffman, E.P. 2000. Expression profiling in the muscular dystrophies: identification of novel aspects of molecular pathophysiology. J. Cell Biol. 151:1321-1336.

39. Haslett, J.N., et al. 2002. Gene expression comparison of biopsies from Duchenne muscular dystrophy (DMD) and normal skeletal muscle. Proc. Natl. Acad. Sci. U. S. A. 99:15000-15005.

40. Porter, J.D., et al. 2002. A chronic inflammatory response dominates the skeletal muscle molecular signature in dystrophin-deficient $\mathrm{mdx}$ mice. Hum. Mol. Genet. 11:263-272.

41. Tkatchenko, A.V., Le Cam, G., Leger, J.J., and Dechesne, C.A. 2000. Large-scale analysis of differential gene expression in the hindlimb muscles and diaphragm of mdx mouse. Biochim. Biophys. Acta. 1500:17-30.

42. Hirata, A., et al. 2003. Expression profiling of cytokines and related genes in regenerating skeletal muscle after cardiotoxin injection: a role for osteopontin. Am. J. Pathol. 163:203-215.

43. Khan, S.A., et al. 2005. Enhanced cell surface CD44 variant $(\mathrm{v} 6, \mathrm{v} 9)$ expression by osteopontin in breast cancer epithelial cells facilitates tumor cell migration: novel post-transcriptional, post-translational regulation. Clin. Exp. Metastasis. 22:663-673.

44. Chabas, D., et al. 2001. The influence of the proinflammatory cytokine, osteopontin, on autoimmune demyelinating disease. Science. 294:1731-1735.

45. Diao, H., et al. 2004. Osteopontin as a mediator of NKT cell function in T cell-mediated liver diseases. Immunity. 21:539-550.

46. Haylock, D.N., and Nilsson, S.K. 2006. Osteopontin: a bridge between bone and blood. Br. J. Haematol. 134:467-474.

47. Mastrogiacomo, M., Derubeis, A.R., and Cancedda, R. 2005. Bone and cartilage formation by skeletal muscle derived cells. J. Cell. Physiol. 204:594-603.

48. Pereira, R.O., et al. 2006. Osteopontin expression in coculture of differentiating rat fetal skeletal fibroblasts and myoblasts. In Vitro Cell Dev. Biol. Anim. 42:4-7.

49. Uaesoontrachoon, K., et al. 2008. Osteopontin and skeletal muscle myoblasts: Association with muscle regeneration and regulation of myoblast function in vitro. Int. J. Biochem. Cell Biol. 40:2303-2314.

50. Shin, T., Ahn, M., Kim, H., Kim, H.M., and Matsumoto, Y. 2006. Increased expression of osteopontin in the heart tissue of Lewis rats with experimental autoimmune myocarditis. J. Vet. Med. Sci. 68:379-382.

51. Okamoto, H. 2006. Osteopontin and cardiovascular system. Mol. Cell. Biochem. 300:1-7.

52. Mylona, E., Jones, K.A., Mills, S.T., and Pavlath, G.K. 2006. CD44 regulates myoblast migration and differentiation. J. Cell Physiol. 209:314-321. 
53. Xie, Z., Singh, M., and Singh, K. 2004. Osteopontin modulates myocardial hypertrophy in response to chronic pressure overload in mice. Hypertension. 44:826-831.

54. Gross, T.S., et al. 2005. Upregulation of osteopontin by osteocytes deprived of mechanical loading or oxygen. J. Bone Miner. Res. 20:250-256.

55. Larkin, J., et al. 2006. CD44 differentially activates mouse NK T cells and conventional T cells. J. Immunol. 177:268-279.

56. Maffia, P.C., et al. 2007. Neutrophil elastase converts human immature dendritic cells into transforming growth factor-beta1-secreting cells and reduces allostimulatory ability. Am. J. Pathol. 171:928-937.

57. Eken, C., et al. 2008. Polymorphonuclear neutrophil-derived ectosomes interfere with the matura- tion of monocyte-derived dendritic cells. J. Immunol. 180:817-824.

58. Pesce, J.T., et al. 2008. Neutrophils clear bacteria associated with parasitic nematodes augmenting the development of an effective Th2-type response. J. Immunol. 180:464-474.

59. D'Avila, H., et al. 2008. Neutrophils recruited to the site of Mycobacterium bovis BCG infection undergo apoptosis and modulate lipid body biogenesis and Prostaglandin E production by macrophages. Cell. Microbiol. 10:2589-2604.

60. Andreetta, F., et al. 2006. Immunomodulation of TGF-beta 1 in $\mathrm{mdx}$ mouse inhibits connective tissue proliferation in diaphragm but increases inflammatory response: implications for antifibrotic therapy. J. Neuroimmunol. 175:77-86.
61. Hartel, J.V., Granchelli, J.A., Hudecki, M.S., Pollina, C.M., and Gosselin, L.E. 2001. Impact of prednisone on TGF-beta 1 and collagen in diaphragm muscle from mdx mice. Muscle Nerve. 24:428-432.

62. Lenga, Y., et al. 2008. Osteopontin expression is required for myofibroblast differentiation. Circ. Res. 102:319-327.

63. Amalfitano, A., and Chamberlain, J.S. 1996. The mdx-amplification-resistant mutation system assay, a simple and rapid polymerase chain reaction-based detection of the $\mathrm{mdx}$ allele. Muscle Nerve. 19:1549-1553.

64. Kramerova, I., Kudryashova, E., Tidball, J.G., and Spencer, M.J. 2004. Null mutation of calpain 3 (p94) in mice causes abnormal sarcomere formation in vivo and in vitro. Hum. Mol. Genet. 13:1373-1388. 